University of South Florida

DIGITAL COMMONS

Digital Commons @ University of

@ UNIVERSITY OF SOUTH FLORIDA

South Florida

QMaSC: A Handbook for Directors of

Quantitative and Mathematics Support Centers

USF Libraries

$1-1-2016$

\title{
24. Case Study: The Mathematics \& Statistics Workshop at Bates College
}

Grace Coulombe

Bates College

Follow this and additional works at: https://digitalcommons.usf.edu/qmasc_handbook

\section{Recommended Citation}

Grace Coulombe (2016), "Case Study: The Mathematics \& Statistics Workshop at Bates College", http://dx.doi.org/10.5038/9780977674435.ch24 in G. Coulombe, M. O'Neill, M. Schuckers (Eds.) A Handbook for Directors of Quantitative and Mathematical Support Centers, Neck Quill Press, http://scholarcommons.usf.edu/qmasc_handbook.

This Case Studies is brought to you for free and open access by the USF Libraries at Digital Commons @ University of South Florida. It has been accepted for inclusion in QMaSC: A Handbook for Directors of Quantitative and Mathematics Support Centers by an authorized administrator of Digital Commons @ University of South Florida. For more information, please contact digitalcommons@usf.edu. 


\title{
Case Study: The Mathematics \& Statistics Workshop at Bates College
}

\author{
(c) Grace Coulombe, \\ Bates College
}

प्र

\section{Introduction}

Bates College is a private, four-year liberal arts college with approximately 1700 students, located in Lewiston, Maine. In the early 1990s, several faculty members recognized the increasing importance of quantitative approaches as an essential part of the intellectual life of the college. Furthermore, they acknowledged the need to provide support for students underprepared to succeed in the natural sciences. As a consequence, the Mathematics and Statistics Workshop (MSW) was created in 2000. Long before the creation of the Workshop, students at Bates were required to satisfy a one course quantitative requirement-a "q-course." It was only with the creation of the MSW that the college endeavored to fully support students in completing that requirement. Therefore, from the outset, the intent was to create a center that would "enable all Bates students, starting from their individual backgrounds, to develop, build on, and take responsibility for their own quantitative skills and understanding." [1] The Math Workshop was aptly named to mirror that of the pre-existing Writing Workshop, which had enjoyed nearly 20 years of successful service to the college prior to the creation of the MSW.

The continuing mission of the Math Workshop is to increase learning in mathematics and quantitative literacy by teaching and tutoring Bates students, as well as supporting the faculty

Suggested Citation: Grace Coulombe (2016), "Case Study: The Mathematics \& Statistics Workshop at Bates College", http://dx.doi.org/10.5038/9780977674435.ch24 in G. Coulombe, M. O'Neill, M. Schuckers (Eds.) A Handbook for Directors of Quantitative and Mathematical Support Centers, Neck Quill Press, http: //scholarcommons.usf.edu/qmasc_handbook

This material is based upon work supported, in part, by the National Science Foundation under Grant DUE1255945. Any opinions, findings, and conclusions or recommendations expressed in this material are those of the author(s) and do not necessarily reflect the views of the National Science Foundation 
across several disciplines. Although it is clear that the MSW seeks to provide enrichment for all q-courses, few professors currently seek assistance in designing q-specific modules for their courses.

Initially the Workshop was centrally located in the old library building. The director's office occupied a room with a two-way mirror overlooking a seminar room formerly used for the observation of psychology experiments. During that first year, the Workshop room housed only one seminar-style table and six chairs and therefore could not support assisting more than 6 simultaneous drop-in visitors. As such, the MSW was plagued with many problems. Because there was insufficient space for both tutors and students to sit, tutors often had to stand while assisting students. The two-way mirror created an awkward dynamic, as students in the Workshop room often felt they were surreptitiously observed by the director from her office. Furthermore, there was no way to control the temperature in the center, which sometimes averaged in excess of 85 degrees.

In 2001, the Workshop moved to a house on the edge of campus, the former home of the history department. The living room of this house, at 319 square feet, became the Workshop room, filled with one large conference table, two small tables each accommodating 1-2 students, one computer, and one chalkboard. The director's office was adjacent to the Workshop room. Gradually, a few small improvements were made through the addition of another chalkboard, a computer upgrade, and the replacement of two small tables with nicer, but still small tables. Because it was separated from the center of campus by a walk of 3-5 minutes, this Workshop space provided a lovely distraction-free zone for students to focus on their work.

However, the space quickly proved too small for the number of students who needed its services. The Workshop room could comfortably accommodate 12 students, but at peak times it was often packed with 18-20 students. At a few times during the semester the MSW might see in excess of 30 students during a 2-3 hour block for drop-in visits, so that it had students sitting on the floor or in the back hallway near the bathroom. The MSW occupied this house for 11 years.

In August of 2012, as part of a wider college initiative to centralize resources, the Math Workshop relocated to the ground floor of the library. This new space, of approximately 1700 square feet, is configured with 4 large tables, 2 medium tables, two small tables, two semi-private cubicles, two computer stations, a projector and screen, a private conference room, a portable chalkboard, and the director's office. In short, the MSW can now comfortably accommodate at least 50 students and tutors simultaneously. The perimeter walls and support pillars are covered with a combination of chalkboards, bulletin boards, and chalkboard paint to allow for most vertical surfaces to double as writing surfaces.

An iPad is used as a dedicated sign-in registry to track visitor usage. Unfortunately, the MSW cannot afford to hire a tutor to sit at a sign-in desk to welcome visitors, ask them to sign-in, and then direct them to a suitable tutor or working group. Consequently, the Workshop occasionally suffers from inconsistency in sign-in practices. Tutors must be reminded regularly to ensure that student visitors sign in on the iPad. 


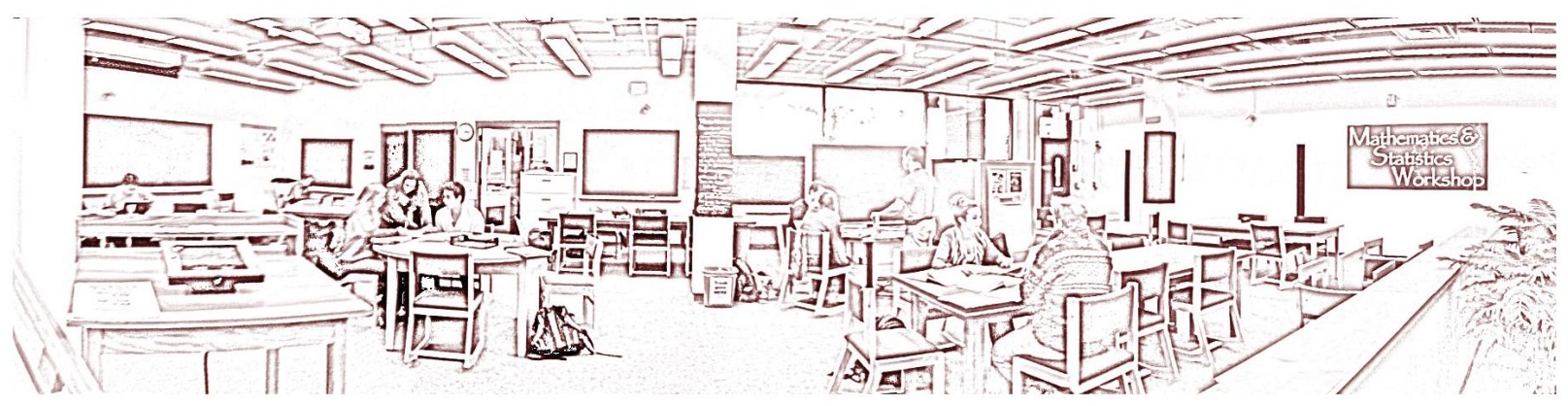

Figure 1: The Mathematics \& Statistics Workshop, 2013

The MSW space is open, with nothing more than a two-foot high bookshelf to delineate the math center from the remaining stacks and group study space on the ground floor of the library. Despite the lack of an enclosing wall, students respect the space as reserved for MSW visitors during open drop-in hours. Outside of drop-in hours, it is common to find a variety of math and science students using the MSW space for group study. Fortunately, the Workshop is not located in or near a designated quiet zone of the library, so the MSW does not receive complaints about the noise level during peak times. The openness and visibility of the Workshop help to promote the idea that the center is available for everyone to use and, most importantly, that there is no shame in seeking assistance.

\section{Center organization and services}

The Math Workshop is led by a full-time director. The director reports to the Dean of the Faculty and submits an annual report each summer detailing the work of the center. The director also holds an appointment as a lecturer and teaches one course per year. The MSW does not have an assistant director or an administrative assistant. All of the work at the center is completed by the director and, on average, 35 peer tutors per academic year.

Support for students comes in a variety of forms and is provided by peer tutors and the director.

- Drop-in Help Sessions: The MSW has morning (Mon.-Fri. 10:30am-12pm), afternoon (Mon.Thurs. 1-4pm, Fri. 1-2:30pm), and evening (Sun.-Thurs. 7-9pm) drop-in hours for students seeking help without an appointment. Students meet with tutors or use the dedicated computers pre-loaded with mathematical and statistical software. At this time, budget constraints prevent the Workshop from having an increased number of drop-in hours. Early mornings are reserved for students to schedule one-on-one private appointments with the director in order to accommodate students who do not thrive in a group tutoring environment.

- Attached Tutors for Selected Courses: In addition to the availability of drop-in hours, each 
section of pre-selected courses has a tutor specifically assigned to work with the students in that class. The list of such courses includes Calculus I, Calculus II, Linear Algebra, Multivariable Calculus, Probability, Mathematical Statistics, and q-courses as needed - such as Working with Data and Great Ideas in Mathematics. Attached tutors attend class at least once per week alongside enrolled students. Depending upon the amount of group work that takes place in the classroom, the attached tutor may also serve in the capacity of a teaching assistant roaming the room to help answer questions. Students schedule appointments, individually or in small groups, to meet with the attached tutor outside of class. Attached tutors also work at least one evening per week in the drop-in center.

- Private Tutoring: Students may request to work individually with a peer tutor in supported math and q-courses. Most private tutoring appointments take place outside of regularly scheduled drop-in hours. (Formerly, subject specific tutoring was administered and funded by the Dean of Students for non-math and non-q-courses. Starting in the fall of 2016, all non-math tutoring will be offered through the newly formed Academic Resource Commons.)

- Support with Technology: Depending upon the expertise of tutors in a given semester, the Workshop provides tutorial sessions to assist students in the use of graphing calculators and software programs including MATLAB, Mathematica, Maple, Prism, SPSS, and the mathematical typesetting program LaTeX.

Support for Faculty — provided solely by the director.

- Class Visits - Classes may either visit the center or the director will visit classes in order to introduce students to the location and services of the MSW. In each case, students are provided with a bookmark detailing MSW services, location, contact information, and the URL for web resources. For some courses, the reverse side of the bookmark is customized to include useful formulas.

- Diagnostic Quizzes and Subsequent Reviews - Upon request, the director works closely with departments and individual instructors to design non-credit-bearing diagnostic quizzes to assess student proficiency with pre-requisite algebra, pre-calculus, or q-skills necessary for a given course. Each department or instructor identifies a threshold for determining sufficient proficiency of the requisite skills. While all students are welcome to attend the subsequent "just-in-time" review sessions, those students scoring below the predetermined threshold are strongly encouraged, and occasionally required, to attend the associated reviews. The number and duration of review sessions is determined by the amount of material the department wishes to be covered. These diagnostic quizzes serve a vital and proactive role in helping to identify at-risk students early in the semester so that they may be connected with appropriate resources. 
For example, the diagnostic quiz for students of Scientific Approaches to Environmental Issues, the methods course for environmental studies majors, focuses on skills using exponents, logarithms, significant figures, dimensional analysis, and linear and exponential models. After the quizzes are scored, the Workshop director and the course instructor discuss the results with the students as well as the resources available, including a targeted review session, for students to improve their proficiency with such skills.

- In-Class Workshops and Guest Lectures - The director works closely with classroom instructors to design and lead in-class workshops or guest lectures as a one-off primer for a given set of topics on quantitative skills to accompany a specific course. Such workshops may also include information on writing with numbers.

For example, the MSW annually visits a class meeting of Interdisciplinary Studies: Methods and Modes of Inquiry, the methods course for students majoring in an interdisciplinary program. Students read, "Size: It's Personal" Chapter 2 of Blastland and Dilnot's The Numbers Game. This reading jumpstarts the conversation about writing with numbers. The authors charge readers to clarify the significance of numbers by asking, "Is that big?" [2] This discussion, coupled with a short primer on basic statistics, provides the starting point of continued class discussions on constructing arguments making use of quantitative data.

\section{Staffing, Hiring and Training}

The hiring of peer tutors is a multi-step procedure consisting of an application, an interview, and training. Interested students start by completing an online application to be a tutor, which asks for information about relevant experience, previous coursework, references, an unofficial transcript, and the types of tutoring roles in which the student is interested. There are multiple tutoring roles within the MSW: drop-in tutors, private tutors, attached tutors, and community tutors. Community tutors are those who wish to work with local high school and community college students, such tutors are not paid by the MSW.

The second stage of the application process consists of a two-part interview, which usually lasts about 30 minutes. Prior to the interview, applicants are provided with a list of math problems they may be asked to solve or discuss during the interview. The applicant first meets with the director to discuss details of relevant experience, as well as the reasons the applicant wishes to be a tutor. In addition, the tutor is asked to discuss the solution to a common math problem with the director. Next, the applicant is interviewed by at least 2 experienced tutors. During this part of the interview, the applicant and tutors engage in a mock tutoring scenario to gauge how the applicant will respond to a variety of common issues that might arise in a tutoring session. After the completion of interviews, the director meets with tutor interviewers to discuss each candidate 
and the associated hiring decision.

The problem-solving and mock tutoring session portions of the interview are crucial in helping to identify potential problem areas for the director to monitor during the first few weeks of work for the new hire. In the cases where an applicant displays considerable nervousness or stumbles through the interview, the applicant may be hired for a probationary period. This tutor will work under close supervision for at least one semester; if acceptable progress is made, then the tutor will be rehired for future semesters. If the tutor does not show improvement, they will not be re-hired.

In short, this two-stage application process coupled with the professorial references arms the director with considerable evidence and subsequent justification on which either to hire or not to hire a given applicant.

Tutors are required to participate in training sessions. The bulk of the training is conducted in a 4.5-hour session. Depending upon scheduling and coordination with other peer-to-peer services on campus, additional 1-hour (or 90-minute) training sessions are offered combining tutors/mentors from the various services. For example, a group training session on ethics is conducted for math, writing, peer science leaders, and non-math subject tutors.

Prior to the initial training session, tutors receive an electronic copy of a tutoring manual addressing topics related to payroll paperwork, submitting time sheets, basic procedures, tutoring goals and responsibilities, general tips, and expectations. Upon arrival at the training session, tutors take an informal quiz to verify that they have read the manual. The 4.5-hour block of training starts with a quick review of selected elements of the training manual, followed by an in-depth series of activities and discussions focused on problem solving, learning styles, strategies for effective sessions, common tutoring scenarios, working one-on-one, working with small groups, and professional behavior.

\section{Community Interactions}

As a member of the faculty, the director is required to serve on a variety of committees, some for a limited amount of time and others indefinitely. The director has served on the following: the Curriculum and Calendar Committee (4 years), the Learning Commons Advisory Group, Faculty Commons Advisory Board, the Peer Writing Coordinator search committee (2007), and the Writing Specialist for the Sciences and Quantitative Writing search committee (2014).

In 2004, when Bates was considering changing distribution requirements, the director participated in researching quantitative reasoning requirements at peer institutions. A primary focus of this research involved taking a team of 3 faculty members to a MAA-PREP Workshop on Quantitative Literacy Across the Curriculum. After returning from the workshop, the director reported to the general education design teams regarding possible directions to take in strengthening the existing q-requirement. One such suggestion included a two-course q-requirement, entitled Q1 and 
Q2, intended to mirror the three-course (W1, W2, W3) writing requirement. This model allowed for Q1 to be completed by means of an introductory quantitative reasoning course (or by passing a q-skills proficiency test). The completion of Q2 would be satisfied by completing any one of several q-courses across the curriculum, but ideally, students would take their Q2-course within with their major. In the end, the design team did not adopt this suggestion, but opted to focus more on other (non-q) features of the general education requirements. As such, the q-requirement at Bates continues to be satisfied through the completion of one course or course equivalent from a pre-approved list. The only change implemented by the design team regarding q-courses was the process by which such courses gain the q-classification. Following the recommendation of the MSW director, the list of criteria for classification of q-courses is based upon readings from Mathematics and Democracy [3].

In 2008, the director spearheaded a Dean of Faculty sponsored workshop on "Expanding Q courses: Beyond the Natural Sciences." Guest speakers were brought in to discuss exciting work done in a selection of humanities or social science based q-courses at peer institutions. Despite an attempt to publicize this event widely, attendance was severely limited due in part to the arrival of a major blizzard coupled with what is considered to be a lack of faculty "buy-in" on non-traditional q-courses.

In early 2009, the Dean of Faculty's office charged a committee, including the MSW director, to revisit the q-requirement and its associated assessment. Bates and Bowdoin Colleges were awarded funds by the Teagle Foundation for a 3-year joint project to design a q-skills assessment test administered to incoming first-year students and a strategy for assessing the college quantitative requirement. The Bates-Bowdoin Quantitative Reasoning (BBQR) collaborative project began with a careful study of Bowdoin's existing q-skills test, redesigning, and piloting the new exam. As a consequence, the q-skills test is now used at both Bates and Bowdoin Colleges. The project also resulted in multiple information sessions and workshops (on both campuses) focused on quantitative reasoning across the curriculum, reasoning from evidence, and how faculty advisors might use the q-skills test results to best advise first-year students. While the BBQR project has ended, work continues at each college regarding next steps.

Despite this seeming endorsement from the college administrators to highlight the need for quantitative reasoning across the curriculum, the wider faculty at Bates has yet to fully embrace that goal. The director's attempts to promote quantitative literacy have not succeeded in reaching beyond the faculty in the natural sciences and those social sciences that frequently utilize statistical tools. Consequently, the majority of services emanating from the Math Workshop are focused on traditional mathematics, scientific, and statistical topics. Rarely does the Workshop get to focus on subtle and nuanced instances of quantitative reasoning embedded in contextual environments in the humanities.

Lastly, the director intermittently collaborates with writing specialists, from the Writing at 
Bates program, to design and conduct a variety of workshops on writing with numbers or presentation feedback for students in courses with a significant quantitative component. Thus far, the workshops on writing with numbers have been only lightly attended, whereas the workshops providing timely feedback for students a few days before they give a public presentation have found more success.

\section{Assessment at the Center}

Every five years the Dean of Faculty's office conducts an internal assessment of the Workshop by soliciting letters and surveys from students and faculty who have used the services of the MSW. The responses, combined with past annual reports and MSW visitor data, are used to evaluate the director and MSW services.

Within the MSW, assessment takes a variety of forms. At the end of each semester, online surveys are used to gather information about the quality of services, the proficiency of the both drop-in and private tutors, and whether or not the physical layout of the MSW is conducive to learning. This information is used to improve the services provided and to determine whether new services may needed.

Statistical summaries regarding the usage of the MSW are generated using the visitor registry data gathered from the iPad sign-in app, private tutoring reports, attached tutoring reports, and sign-in data from specialized help sessions and workshops. This data is included as part of the annual report submitted to the Dean of the Faculty each August.

The following is a sub-collection of a data summary provided to the Dean of the Faculty regarding the usage statistics of the MSW in 2012-2013:

- 408 students used at least one service of the Math Workshop.

- 2005 drop-in tutoring sessions were provided to 398 students.

- 517 private tutoring sessions totaling 741 hours were provided to 47 students.

- 91 students scheduled 337 private tutoring sessions with their attached tutor totaling 307.75 hours. (In 2012-2013, each section of Calculus I, Calculus II, and Probability was assigned an attached tutor for the semester due to anticipated high demand for private tutoring.)

- 10 students used private tutoring services only, no drop-in hours.

- 3031 combined interactions with students: private tutoring, drop-in help, and formal review sessions. (This number doesn't include informal advising meetings.)

- $76 \%$ of all drop-in tutoring sessions were devoted to Calculus.

- $54 \%$ of the afternoon drop-in sessions were devoted to Calculus. 
- $50 \%$ of students seeking assistance were first years, $28 \%$ were sophomores, $13 \%$ were juniors, and $9 \%$ were seniors.

- 47 students received private tutoring in the following topics: GRE Prep, Pre-calculus review, Calculus I and II, Linear Algebra, Multivariable Calculus, Abstract Algebra, Introduction to Abstraction, Intermediate Microeconomics, Econometrics, and Statistics for Economics.

- 3 consultations provided for Senior Thesis students majoring in geology, biology, and environmental studies.

- The 54 peer tutors employed by the Workshop had majors in Mathematics, Physics, Chemistry, History, French, Spanish, Music, Art and Visual Culture, Biology, Biological Chemistry, Engineering (3-2 program), Economics, and Politics.

\section{Additional Remarks}

Many of the obstacles encountered in the life the Math Workshop are similar to those of most QMaSCs at similar institutions. Finding a suitable space, both sufficiently large and comfortable, was certainly a challenge. However, patience won out, and the MSW currently occupies a space large enough to accommodate the future growth of program offerings as well as any potential increase in the number of daily visitors.

Likewise, the MSW continues to face challenges in securing sufficient funding. In the mid-2000s, the director rightly argued that math/q-tutors deserved a higher wage compared with other campus jobs that do not require specialized knowledge or formal training. The Office of Student Employment (SEO) agreed to a wage increase to $\$ 10$ per hour for all trained MSW tutors. Unfortunately, the economic crisis of 2008, coupled with an increased demand for tutors, caused the MSW to exceed its budget for several years in a row. Consequently, the director struck a deal with the Dean of the Faculty (DOF) and SEO to reduce the wage of trained tutors to $\$ 8.50$ per hour in exchange for an additional $\$ 7000$ per year in the budget allocated to the MSW for student wages. This budget increase is a testament to the valuable services provided by the MSW and the DOF's commitment to providing academic resources; however, the MSW tutors continue to be underpaid compared to tutors and mentors at peer institutions.

The MSW continues its never-ending campaign of fostering a reputation as a location providing valuable services that are not limited to remedial mathematics. By far, the most effective means of promotion and public relations comes from word-of-mouth recommendations by the students who repeatedly use the Workshop's services. Class visits by the director alone can never compete with a strong testimonial from a friend or classmate when students are considering whether or not to visit the Workshop. 
The director regularly posts a "Problem of the Week" on the central support pillar of the Workshop. The first three students to solve the puzzle earn their choice of a puzzle or a lightweight messenger bag bearing the MSW logo. Repeatedly, the problem of the week captures the attention of students who are merely wandering through the ground floor of the library. Most often, students who regularly visit the workshop are among the winners, but the list of previous winners also includes those not enrolled in any math, science, or q-course. In some cases, the winners have inquired about the possibility of becoming a math tutor.

Directors who are new to running a QMaSC or who are creating a QMaSC from the ground up should expect to encounter their fair share of obstacles. A healthy dose of patience is required as a director works to gain faculty buy-in for activities and programs surpassing remedial support, building a reputation for providing valuable services, bargaining for a space that allows for expansion, and advocating for staff and student workers.

\section{Bibliography}

[1] D. Haines, L. Malloy, C. Schwinn, and A. Scott, "Proposal for the Establishment of the Bates College Mathematics Center." submitted to the Bates College Administration, July 1998.

[2] M. Blastland and A. W. Dilnot, The Numbers Game: The Commonsense Guide to Understanding Numbers in the News, in Politics, and in Life.. New York: Gotham Books, 2010.

[3] L. A. Steen, Mathematics and Democracy: The Case for Quantitative Literacy. Princeton, NJ: National Council on Education and the Disciplines, 2001.

\section{Acknowledgements}

I would like to extend my sincerest appreciation to Misty Beck, Writing Specialist in the Social Sciences and Interdisciplinary Programs at Bates for her thoughtful comments on drafts of this case study. Likewise, I am thankful for the support and advice of Hillory Oakes, the former director of Writing at Bates. My heartfelt thanks are offered to Michael Schuckers and Mary ONeill for their comments on the early drafts of this document. Lastly, I would like to thank the National Science Foundation for its generous support of the QMaSC Handbook project through NSF grant number 1255945 . 


\section{$9 \quad$ Appendix}

\section{Links to web forms:}

Tutor Job Application

http://www.bates.edu/math-stat-workshop/for-tutors/tutor-job-application/

Tutor Request Form

http://www . bates.edu/math-stat-workshop/for-students/private-tutor-request-form/

Bi-Weekly Private Tutoring Report Form

http://www . bates.edu/math-stat-workshop/for-tutors/private-tutoring-report-form/

Bi-Weekly Attached Tutoring Report Form

http://www.bates.edu/math-stat-workshop/for-tutors/attached-tutor-activities-report-form/

Private Tutor Evaluation Form

http://www.bates.edu/math-stat-workshop/private-tutor-eval/

Drop-in Hours Evaluation Form

http://www . bates.edu/math-stat-workshop/drop-in-eval/ 


\section{Sample Bookmarks for Students of Calculus}

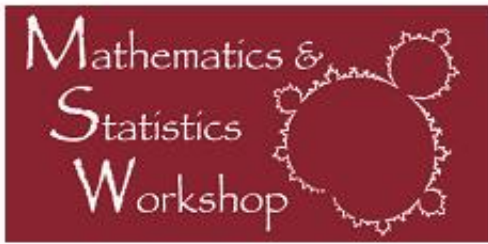

Lataion: Grounc: Flowr Lattel Library

Direstur: Gäec Coudunbe

\section{FALL AND WINTER SEMESTERS}

Drop-in llours: 14 p.m. ilen, Thersi,

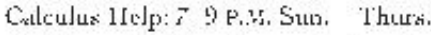

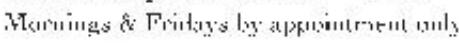

\section{SHORT TERM}

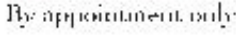

\section{TO MAKE AN APPOINTMENT}

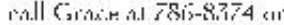

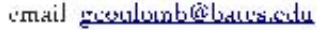

\section{MATH WORKSHOP SERVICES}

- Lrep-Ir sludenes ate weleorno lo dive

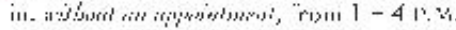

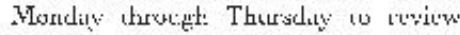
iriath topics ils needed or lo llse dis

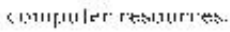

- Privale Tuloring unt-in-ena belp witi a peer tuler ill sour conpeniense.

- Colculns Hilp Sissions - nightoly idrop

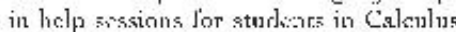
$I$ and II sta:-'at by pece turors whicis mer. Sundive - Thursday from $7-9$

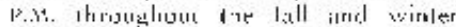
stemestrints.

- Atcached Jitor- Fro Mach 105 alst 106 studencs may malic appointments to work onc-or-one with the rutor specilically assigned to their scetion of

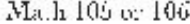

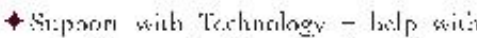
grspling calsulators snd solroware programs such as Mal'tall. Minitah, klayle, SIsis, and the mathemarical trpesetr:ת prostam Lalidi.

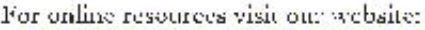

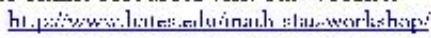

Back of Calculus Boolemark
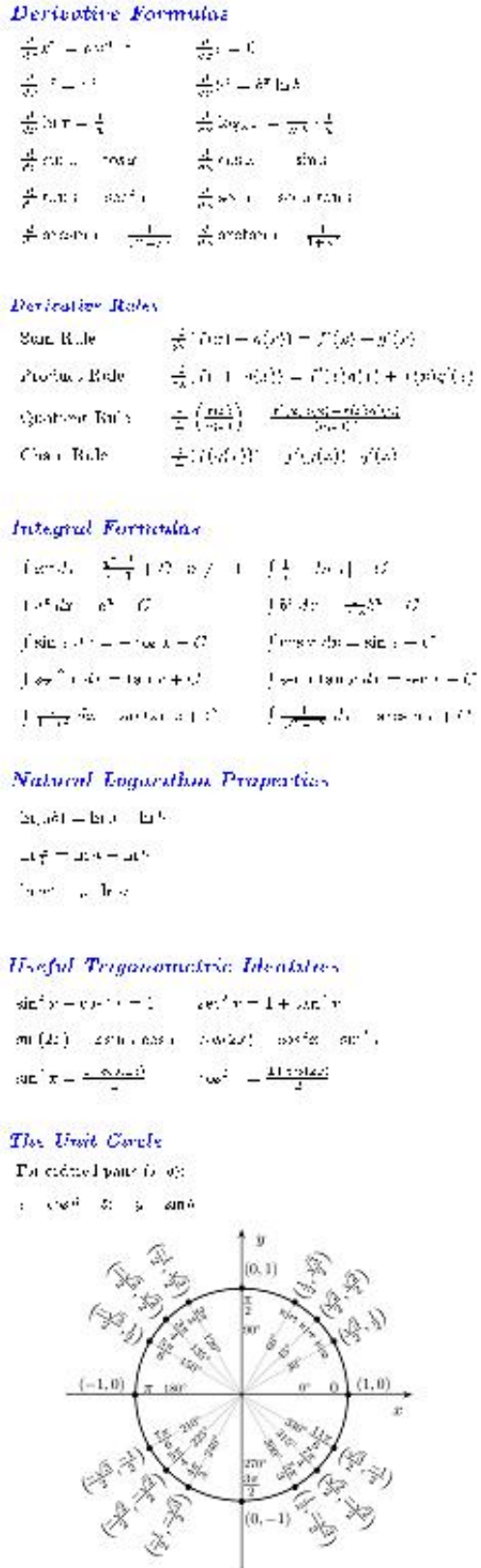

Back of' Liny. Studies Buukman'k

Exponent Proptraties

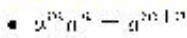

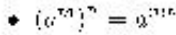

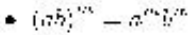

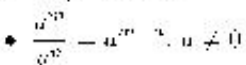

- $\left(\frac{c}{i}\right)^{n+}-\frac{e^{n}}{n^{n !}}, i \frac{1}{1} \|$

- $\therefore$ " $\frac{1}{a^{n !}}: n \div 0$

- $n_{3}^{\frac{1}{4}}=\sqrt{3}$

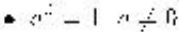

\section{legenwithms}

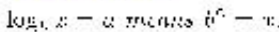

: $11 \mathrm{~b}, \mathrm{~s}, \mathrm{~s}, \mathrm{l}$

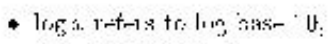
ic.

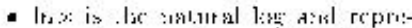

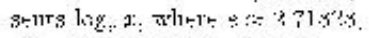

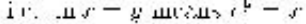

Corrtrian Morlels

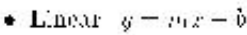

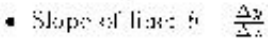

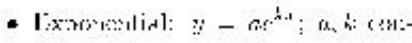
stant

Geowedric Formulas

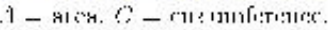

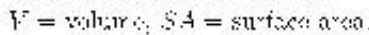

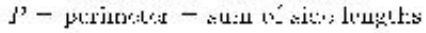

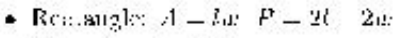

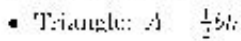

- Virch: $A-\pi \pi^{2}, 6-2 \pi$

- 'Japuxsix:: $A--i b_{1} \mid b_{2}: i_{2}$

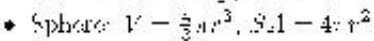

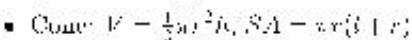

Motric Contersion Prefixes

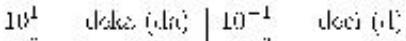

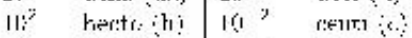

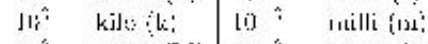

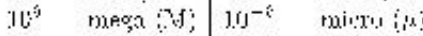

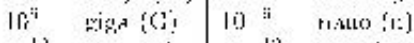

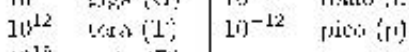

